\title{
A poor international standard for trap selectivity threatens carnivore conservation
}

\author{
Emilio Virgós ${ }^{1 \ddagger}$, Jorge Lozano ${ }^{1,2 \ddagger}$, Sara Cabezas-Díaz ${ }^{3}$, David W. Macdonald ${ }^{4}$, Andrzej Zalewski ${ }^{5}$, Juan Carlos \\ Atienza $^{3}$, Gilbert Proulx ${ }^{6}$, William J. Ripple ${ }^{7}$, Luis M. Rosalino ${ }^{8}$, Margarida Santos-Reis ${ }^{8}$, Paul J. Johnson ${ }^{4}$, \\ Aurelio F. Malo ${ }^{9}$ and Sandra E. Baker ${ }^{4}$ \\ ‡ Both authors contributed equally
}

(1) ESCET, Departamento de Biología y Geología, Universidad Rey Juan Carlos, C/Tulipán s/n. 28933 Móstoles, Spain. emilio.virgos@urjc.es

(2) Departamento de Ciencias Naturales, Sección de Biología Básica y Aplicada, Universidad Técnica Particular de Loja, San Cayetano Alto, C/París s/n. Loja 1101608, Ecuador. j.lozano.men@gmail.com

(3) Área de Conservación de Especies y Espacios, SEO/BirdLife. C/ Melquíades Biencinto 34. 28053 Madrid, Spain. Sara: scabezas@seo.org Juan Carlos: jcatienza@seo.org

(4) Wildlife Conservation Research Unit, Department of Zoology, University of Oxford, The RecanatiKaplan Centre, Tubney House, Abingdon Road, Tubney, Abingdon, OX13 5QL, UK. David: david.macdonald@zoo.ox.ac.uk Sandra: sandra.baker@zoo.ox.ac.uk Paul: paul.johnson@zoo.ox.ac.uk

(5) Mammal Research Institute, Polish Academy of Sciences, 17-230 Białowieża, Poland. zalewski@ibs.bialowieza.pl

(6) Alpha Wildlife Research \& Management Ltd., 229 Lilac Terrace, Sherwood Park, Alberta, T8H 1W3, Canada.gproulx@alphawildlife.ca

(7) Trophic Cascades Program, Department of Forest Ecosystems and Society, Oregon State University, Corvallis, OR, USA. bill.ripple@oregonstate.edu

(8) CE3C- Centre for Ecology, Evolution and Environmental Changes, Faculdade de Ciências, Universidade de Lisboa, 1749-016 Lisboa, Portugal. Luis M.: Imrosalino@fc.ul.pt Margarida: mmreis@fc.ul.pt

(9) Department of Zoology, University of Oxford, The Tinbergen Building, South Parks Road, OX1 3PS, Oxford, UK. aurelio.malo@zoo.ox.ac.uk

Correspondence Author: Emilio Virgós. ESCET, Dpt Biología y Geología, Universidad Rey Juan Carlos. C/ Tulipán s/n 28933 Móstoles (Madrid), Spain. Phone: +34-914888103. EMail: emilio.virgos@urjc.es 


\section{Abstract}

Unintentional mortality of endangered carnivores due to non-selective trapping is important for conservation and warrants urgent attention. Currently, non-selective traps are being approved and used based on trap selectivity tests conducted according to International Organization for Standardization (ISO) guidelines. We review these guidelines and find them inadequate, because: 1) the ISO definition of selectivity does not account for relative abundance of target and non-target species and does not therefore meaningfully reflect selectivity; 2) the guidelines methodology at best quantifies relative selectivity of one trap against another, which is of limited use unless the control trap is known to have an acceptable level of absolute selectivity for the target species; 3) information on relative trap selectivity cannot simply be extrapolated elsewhere, unless species assemblage and relative species abundances are consistent. We demonstrate that the ISO definition of trap selectivity is only a simple capture proportion and therefore does not represent trap selectivity. ISO guidelines on trap selectivity should be reviewed to reflect particular ecological scenarios and we suggest how this might be done. Policy-makers, practitioners and researchers should interpret scientific results more cautiously. Trap approval decisions should be based on scientific evidence to avoid undermining the conservation of biodiversity.

Keywords: endangered species, ISO standards, non-target species, predator control, selectivity, wildlife management 


\section{列}

resources, such as meat or fur, among others. Wild predators are also trapped widely to protect human interests such as farming, ranching, game shooting and conservation (e.g. Reynolds and Tapper 1996; Lozano et al. 2013). However, non-selective trapping can have serious impacts on non-target populations (e.g. Virgós and Travaini 2005), by causing population decline and regional/national extinction (in for example bears, lynxes, wolves, mustelids and wild cats; see Council of Europe 1993; Breitenmosser 1998; Cabezas-Díaz et al. 2009; Lozano and Malo 2012; Ripple et al. 2014). Since the 1970s, because of population declines and threats associated with predator control programs (Lozano et al. 2013), vulnerable predator species have been protected by international and national laws (as, for example, by the Washington Convention or CITES in 1975, and the Spanish Law 4/1989 for nature protection) and non-selective trapping devices have been banned in Europe (Bern Convention in 1979, and the European Birds and Habitats Directives, approved in 1979 and 1992, respectively). Despite the widespread ban on non-selective traps, they continue to be used in most European countries (e.g. Council of Europe 1993; Virgós and Travaini 2005; Lozano and Malo 2012), as well as many other areas around the world (see Iossa et al. 2007), and consequently remain a threat to the conservation of predators and other non-target animals (Lozano et al. 2013). Likewise, non-selective traps remain a potential threat to overall biodiversity due to the demonstrated role of carnivores in maintaining healthy ecosystems (reviewed by Ripple et al. 2014).

7 In 1999, the International Organization for Standardization (ISO) produced 98 internationally-adopted methods for testing various aspects of the performance of both killing 99 and restraining traps for mammals, including trap selectivity (ISO 1999a,b). Traps are being 
tested and approved based on these ISO standards worldwide. We review the ISO trap standards and, in particular, the definition of selectivity used, showing that those standards are flawed and present a serious threat to the conservation of endangered carnivore species.

\section{Measuring trap selectivity}

The stated principle of the ISO trap selectivity tests is to evaluate, in the field, the capability of a trap to capture target rather than non-target animals, by recording the number of both that are captured by the test trap, and by a control trap. ISO specify that experimental and control traps should be placed "in the same substrate and/or vegetation type in pairs, with appropriate separation for the target animals, or alternatively within the trap layout using random assignment and the bait or lure recommended by the manufacturer”. For killing traps, ISO define a control trap as the "most commonly used trap (of the killing, or submersion restraining type) for the target animal which is used in accordance with the killing-trap system established through most commonly used practice. This will be determined by the authority using this part of ISO 10990, such as a nationally recognized certification body” (ISO 1999a, see also ISO 1999b for similar wording regarding restraining traps). According to the ISO methods, trap 'selectivity' is calculated as follows:

Selectivity $=$ Number of captured target animals $/$ Total number of captured animals 'when resources (i.e. animals) are observed disproportionately to their availability, use (i.e. trapping) is said to be selective'. Unfortunately, the ISO definition does not consider the 
availability of animals in the environment (see also below). Nevertheless, the ISO guidelines are intended for testing the suitability of new traps for general use, by allowing aspects of a new trap to be compared with those of an established (control) trap (ISO 1999a,b; Iossa et al. 2007). Such a comparison would be expected to indicate whether or not the test trap is more or less selective for the target species than the control trap. At best, this would provide a measure of the relative selectivity of one type of trap compared to that of another, but not of the absolute selectivity. The ISO definition of selectivity (1999a,b), should be readdressed for three reasons:

1) The ISO definition of selectivity does not take into account the relative abundance of target and non-target species and represents only a simple rate or capture proportion (as defined above), which is not the same than a true selectivity index (Manly et al. 2002). If traps are completely non-selective, and capture individuals of different species (including the target species) at random, then this metric will simply reflect the relative abundance of the target species in test areas. At worst, it could disguise selectivity for a (potentially endangered) non-target species, resulting in unpredictable (and potentially deleterious and irreversible) consequences. Although the ISO methodology specifies evaluating test traps and control traps alongside each other, presumably to determine whether one is relatively more selective than the other, it is not stated explicitly that they need to be tested where the species assemblage and relative species abundances are similar.

2) The ISO guidelines do not consider measuring absolute selectivity for the target species. Information about the relative selectivity of one trap compared to another will be useful only if the control trap is already known to have an acceptable level of absolute selectivity. Moreover, no threshold value of trap selectivity is provided. 
3) The ISO method does not account for the fact that the species assemblage and relative species abundance in the test area may not be representative of those elsewhere. The results of a comparison of two trap types in one area (even where species assemblage and relative species abundance are similar for testing both traps) cannot simply be extrapolated elsewhere.

The habitat selection and dietary preference literature has already dealt with and discussed widely the issues arising from not considering relative species abundance (reviewed in Manly et al. 2002). It is generally agreed that no conclusions can be drawn about habitat or resource selection (i.e. selectivity) without a robust estimate of the relative availability of habitats or resources in the study area. Likewise, indices of trap selectivity should be based on algorithms which use estimates of species availability (Manly et al. 2002). An example of an appropriate index of trap selectivity is Savage's W index, a selectivity index used in different ecological applications related to the selection of resources (see Manly et al. 2002), which can be expressed for our purposes as:

$\mathrm{W}=$ Capture proportion / population proportion

where the numerator alone (capture proportion) corresponds to the current ISO index for trap selectivity. The denominator (population proportion) is that proportion of the entire population of possible trapped animals (of all species) made up of members of the target species. A value of 1.0 for $\mathrm{W}$ indicates no selectivity. 
176

177

178

179

180

181

182

183

184

185

186

187

188

189

190

191

192

193

194

195

196

197

198

199

To demonstrate the inadequacy of the ISO selectivity index to quantify selectivity we compared results obtained using the ISO index with those derived from Savage's index (W;

Manly et al. 2002). We considered five hypothetical scenarios using different capture proportions (as mentioned before, capture proportion equates to the ISO selectivity index) and realistic values for relative species abundance, and capture sample sizes (we considered a total sample of twenty captured animals for each scenario). The captures were hypothesised to be of four common carnivore species in Mediterranean environments, as derived from the literature (data for red foxes Vulpes vulpes, Cavallini and Lovari 1994; stone martens Martes foina, Genovesi et al. 1997; Eurasian badgers Meles meles, Rosalino et al. 2004; and European wildcats Felis silvestris, Monterroso et al. 2009). It is realistic to visualise that foxes are the target species while the others are non-target species. Expected capture frequencies for each scenario were calculated according to relative species abundance (if individuals of each had equal likelihood of capture). Results are shown in Table 1. W, Savage's index, is not constrained and can range numerically between zero and infinity. For all scenarios considered we visualised that foxes were $64 \%$ of the community while the other species represented 36\%. In scenarios in which fox capture proportions were 0.6, 0.7 and 0.8 with the other captures being non-target, $\mathrm{W}$ for foxes ranged between 0.94 and 1.25, where 1.0 indicates capture of foxes consistent with no selectivity (Table 1). If W values differing from 1 indicate selective capture of foxes, a W of statistically significantly less than 1 indicates fewer fox captures than expected and a W of significantly greater than 1 indicates more fox captures than consistent with no selectivity (see Manly et al. 2002). At the higher fox capture proportions in our analysis $(\geq 0.9)$, W exceeded 1 by a larger margin than in the scenarios where it was $<0.90$ (it was 1.41 and 1.48 respectively), indicating greater 
selectivity for this species. The selectivity present where fox capture proportion was <0.9) did not result in statistically significant selectivity $\left(\chi^{2} \leq 2.22, \mathrm{P} \geq 0.14\right)$. In scenarios where fox capture proportion was $\geq 0.9$, selectivity for foxes was statistically significant $\left(\chi^{2} \geq 5.87\right.$ $\mathrm{P} \leq 0.02$ ). These results relate to the exact (and realistic) sample sizes used here. Of course, if sample sizes were large enough there would be sufficient statistical power to detect effect sizes of the magnitudes illustrated in Table 1 for all scenarios. For example, for the effect size in scenarios where fox captures are $0.6,0.7$ and 0.8 of the total, statistical power does not reach 0.90 (that is, the incorrect null hypothesis is rejected with a probability of 0.90 ), until total sample sizes reach 2,391, 1055, and 149 respectively (calculated with GPower; Faul et al. 2009).

Interestingly, in scenarios 1 and 2, $\mathrm{W}$ was greater for wildcats than for foxes (Table 1). This demonstrates that where species availability is taken into account, it is quite possible to detect greater selectivity for a non-target endangered species than for the target species. In other words, tThis simple simulation demonstrates how different estimates of selectivity can result from the same capture data, depending on whether a simple rate (capture proportion) or a true selectivity index is used.

Using a simple graphical model we show that the capture proportion is not an appropriate index of trap selectivity (Fig. 1). We show how the selectivity index, B (W, standardised to constrain values between 0 and 1, e.g. W for one species / sum of $\mathrm{W}$ for all species, with values close to 0 and 0.5 indicating non selectivity and only values close to 1 indicating selectivity), changes according to the relative abundance of two species in a community, when the capture proportion for the two species remains constant. Where relative abundance for species 1 is high and that for species 2 is low, the standardised index of selectivity (B), for species 1 is small and that for species 2 is large. Where species 1 is present at low relative abundance and species 2 at high relative abundance, the relative values for $\mathrm{B}$ 
are reversed: large for species 1 and small for species 2 (Fig. 1). These two simple examples using identical capture proportions demonstrate clearly the importance of considering relative species abundance in determining the selectivity of a trap, and that raw capture proportions can overestimate or underestimate selectivity.

In summary, Table 1 and Fig. 1 show that: 1 ) the ISO selectivity index is a defective index of selectivity; 2) for a community comprising foxes, wildcats, badgers and stone martens, in the relative species abundances shown, trap selectivity for red foxes could be demonstrated only for the realistic sample size considered when capture proportions are 0.9 or greater (where the proportion is lower, the statistical test fails to reject the $\mathrm{H}_{0}$ of 'no selectivity’ a type 2 error); and 3) good quality information, on species occurrence and their relative abundance, is required to determine the selectivity of a trapping device (according to arguments by Manly et al. 2002).

\section{Potential risks for carnivore conservation}

$$
\text { Our approach illustrates how deriving indices using concepts not supported by }
$$
ecological theory can generate spurious results (see Anderson et al. 2001). The effects can be damaging for conservation if, for example, environmental authorities base decisions regarding the legality of traps upon them. Defective ISO-like indices of selectivity (in the sense that they are merely capture rates) are being used worldwide for testing traps, e.g., in Australia (Fleming et al. 1998), South America (Luengos-Vidal et al. 2003), USA (e.g. Shivik et al. 2005), Canada, Europe and Africa (see 15 studies reviewed by Iossa et al. 2007). In the study case of Spain, authorities are encouraging both the testing of trap selectivity specifically using the ISO guidelines, and the participation of administration technical staff in the scientific teams carrying out the studies - the results thus obtain the formal support of the authorities. 
As a consequence, the Ministry of Agriculture, Food and the Environment in Spain

251 (MAGRAMA) has decided that a number of traps are selective for red foxes (MAGRAMA 2011), based on studies conducted by Muñoz-Igualada et al. (2008, 2010). The impact of this is that regional Spanish authorities are now widely considering granting legal approval for the use of certain traps on hunting grounds, including Spanish traditional snares (allegedly selective, according to Muñoz-Igualada et al. 2008, 2010, and the ISO standards). However, this type of snare accounts for the largest proportion of recorded mortality of the most endangered Iberian predator, the Iberian lynx Lynx pardinus (Rodríguez and Delibes 2004,

Cabezas-Díaz et al. 2009), clearly showing that these traps are not selective. Following guidelines produced by MAGRAMA (2011), the Autonomous government of Castilla La Mancha region approved Order 18/06/2013, which allows the use of several purportedly 261 selective traps for foxes, including both traditional and new designs of snare. Following this 262 Order, the deployment of 1,207 snares was approved in two provinces bordering the critically 263 endangered population of Iberian lynx, jeopardising the survival of dispersers and 264 colonisation of new areas, hence putting at serious risk the survival of the most threatened 265 felid in the world (in fact, an Iberian lynx was captured in one of these approved snares in 266 May 2015; see Iberlince 2015). Likewise, non-selective trapping (due to the use of putative selective devices 268 according to ISO index or similar) of red foxes in Europe may jeopardize other endangered 269 species, such as the European wildcat (Lozano and Malo 2012), and populations of two key 270 species for maintaining ecosystem function, the Eurasian lynx Lynx lynx and the grey wolf 271 Canis lupus (Breitenmoser 1998; Ripple et al. 2014). Snares designed to capture coyotes 272 Canis latrans in North America (e.g. Shivik et al. 2005) could also catch wolves and other 273 species. Furthermore, trapping of South American foxes, such as the pampas fox Pseudalopex 274 gymnocercus, could lead to the depletion of endangered neotropical felids (Luengos-Vidal et 
al. 2003). Therefore, similar studies are needed in these regions, dealing with these carnivores and others, to test if the pattern found in Spain is being repeated elsewhere.

Although many devices are designed to capture mainly carnivores, many taxa are also negatively affected by non-selective trapping. For example, they often catch substantial numbers of non-target mammals, e.g. ungulates and lagomorphs, endangered birds (eagles, hawks, owls, vultures, etc) and even reptiles (see Fleming et al. 1998; Luengos-Vidal et al. 2003; Shivik et al. 2005; Iossa et al. 2007; Garrido 2008; Muñoz-Igualada et al. 2008, 2010). Furthermore, it is logical to expect that changes in populations of large carnivores, such as wolves, dingoes Canis dingo and big cats, including lynxes and pumas Puma concolor, might cause profound changes to ecosystem structure and function, due to negative cascading effects, which can potentially affect plant, bird, mammal, herpetofauna, and invertebrate richness or abundance, as well as soil erosion and stream morphology (see Ripple et al. 2014). So, the urgent study of the effect of the ISO standards-based trapping (wherever this is performed) upon structure and function of ecosystems, is also of the major importance. ISO standards in general are internationally respected and authorities would be willing to adhere to them as a sign of good practice. But if the ill-defined concept of ISO selectivity remains unchanged, the approval of non-selective traps based on capture proportion data will be extended elsewhere in Europe and beyond, further undermining attempts to conserve carnivore communities and, in the worst case, overall biodiversity (Lozano et al. 2013; Ripple et al. 2014).

\section{The source of the ISO problem}


guidelines consist not only of scientists, but of different and often opposing stakeholders

301 (Harrop 1998; Iossa et al. 2007). ISO guidelines tend to be the result of negotiation among conflicting interest groups, often based on little more than incomplete minimum agreements methodologies may not be consistent with scientific knowledge (as it is the case considering the concept of selectivity, Manly et al. 2002) and/or sufficiently accurate (Powell and Proulx 2003; Harris et al. 2005; Iossa et al. 2007; Proulx et al. 2012). and Yach 2001), and call for independent tests of scientific consistency as a condition for validating ISO guidelines.

\section{Conclusions and recommendations}

(i.e. according to scientific methodology), by accounting for relative species abundance, extremely labour-intensive and we certainly do not under-estimate the scale of additional selectivity.

The definition of trap selectivity used in the current ISO guidelines is flawed, as demonstrated here, and approving traps using these guidelines poses a threat to the conservation of endangered species, such as, for example the Iberian lynx in Spain. Policymakers should redraft the ISO guidelines, which are inadequate. Importantly, trap selectivity should be redefined, to incorporate the relative abundance of species; for example, Savage's 
325 W index (with a threshold value $\geq 1.4$ indicating selectivity) or similar could be used (see

326 Manly et al. 2002). Traps in current use should be reassessed according to the new definition.

327 The ISO guidelines should clarify the difference between relative and absolute selectivity.

328 The guidelines also need to specify how the two measures of selectivity can be legitimately

329 used, and clarify that measures of selectivity cannot simply be extrapolated elsewhere.

330 In field tests, trap setting and checking should be done consistently (the basic design

331 indicated by ISO standards being correct). Tests should be conducted under comparable

332 ecological conditions (considering not only vegetation type, but also weather, season, species

333 assemblage, etc), and accounting for temporal variation in selectivity. To take into account

334 population proportion (in order to consider animal availability), and calculate correct values

335 of the $\mathrm{W}$ index (or similar), previous estimates of animal populations should be obtained, by

336 applying standard census techniques (e.g. Sutherland 2006; Long et al. 2008; O’Connell et al.

337 2011).

338 Furthermore, wildlife researchers with experience in animal trapping need to be as

339 involved as policy-makers in the drafting of policies. Both researchers and authorities

340 interpreting research on trap selectivity need to be mindful of what they mean by 'selective'; a

341 trap can be relatively more selective than another but may not be of adequate absolute

342 selectivity, threatening endangered carnivores as a consequence. What is happening in Spain

343 could also occur in other countries, this case providing a basis of concern for conservationists.

344 We recommend that further studies are conducted outside Spain and Europe in order to obtain

345 a more global perspective of the scope of the problem.

346 Where selective devices for trapping or controlling animals are not yet available,

347 selective procedures such as shooting, or habitat management, can be applied where

348 appropriate. New traps can also be developed; these will need to be tested for absolute

349 selectivity using the new ISO standards before approval. 


\section{Acknowledgments}

353

Jorge Lozano was supported by a Prometeo Fellowship from the SENESCYT, a national agency for Education and Science of the Government of Ecuador. Sandra Baker was supported by a Fellowship from the Humane Society International UK, and the Baker Trust. DWM was supported by the Recanati-Kaplan Foundation, the Robertson Foundation and the the "Fundação para a Ciência e a Tecnologia” and "Fundo Social Europeu” (III Quadro

Comunitário de Apoio) (SFRH/BPD/35842/2007). Paul Johnson acknowledges the support of the Whitley Trust. Aurelio F. Malo was partly supported by an ERC grant (249872).

\section{References}

Anderson DR, Burnham KP, Gould WR, Cherry S (2001) Concerns about finding effects that are actually spurious. Wildlife Soc B 29:311-316

Bialous SA, Yach D (2001) Whose standard is it, anyway? How the tobacco industry determines the International Organization for Standardization (ISO) standards for tobacco and tobacco products. Tob Control 10:96-104

Breitenmoser U (1998) Large predators in the Alps: The fall and rise of man's competitors. Biol Conserv 83:279-289

372 Cabezas-Díaz S, Lozano J, Virgós E (2009) The declines of the wild rabbit (Oryctolagus cuniculus) and the Iberian lynx (Lynx pardinus) in Spain: redirecting conservation efforts. In: Aronoff JB (ed) Handbook of nature conservation: global, environmental 
and economic issues. Nova Science Publishers Inc., Hauppauge, pp 283-310

376 Cavallini P, Lovari S (1994) Home range, habitat selection and activity of the red fox in a Mediterranean coastal ecotone. Acta Theriol 39:279-297

Council of Europe (1993) Seminar on the biology and conservation of the wildcat (Felis silvestris). Council of Europe, Strasbourg

Faul F, Erdfelder E, Buchner A, Lang A-G (2009) Statistical power analyses using G*Power

Fleming PJS, Allen LR, Berghout MJ, Meek PD, Pavlov PM, Stevens P, Strong K, Thompson JA, Thomson PC (1998) The performance of wild-canid traps in Australia: efficiency, selectivity and trap-related injuries. Wildlife Res 25:327-338

Garrido JL (2008) Especialista en control de predadores. FEDENCA - Escuela Española de Caza, Madrid

Genovesi P, Sinibaldi I, Boitani L (1997) Spacing patterns and territoriality of the stone marten. Can J Zoolog 75:1966-1971

Harris S, Soulsbury CD, Iossa G (2005) Trapped by bad Science. The myths behind the International Humane Trapping Standards. International Fund for Animal Welfare, Brussels

Harrop SR (1998) The Agreement on international humane trapping standards - Background, critique and the texts. J Int Wildl Law Pol 1:387-394

Harrop SR (2000) The international regulation of animal welfare and conservation issues through standards dealing with the trapping of wild mammals. J Environ Law 12: 333360

Iberlince (2015) El proyecto Life+IBERLINCE activa exitosamente el protocolo para devolver a Llera a Sierra Morena. 

Rde Accesed 30 October 2015

401

402

403

404

405

406

407

408

409

410

411

412

413

414

415

416

417

418

419

420

421

422

423

International Organization for Standardization [ISO] (1999a) TC191. Animal (mammal) traps. Part 4: methods for testing killing trap systems used on land or underwater. International Standard ISO/DIS 10990-4. International Organization for Standardization, Geneva

International Organization for Standardization [ISO] (1999b) TC191. Animal (mammal) traps. Part 5: methods for testing restraining traps. International Standard ISO/DIS 10990-5. International Organization for Standardization, Geneva

Iossa G, Soulsbury CD, Harris H (2007) Mammal trapping: a review of animal welfare standards of killing and restraining traps. Anim Welfare 16:335-352

Long RA, MacKay P, Zielinski WJ, Ray JC (2008) Noninvasive Survey Methods for Carnivores. Island Press, Washington, Covelo, London

Lozano J, Malo AF (2012) Conservation of European wildcat (Felis silvestris) in Mediterranean environments: a reassessment of current threats. In: Williams GS (ed) Mediterranean Ecosystems: Dynamics, Management and Conservation. Nova Science Publishers Inc., Hauppauge, pp 1-31

Lozano J, Casanovas GJ, Virgós E, Zorrilla JM (2013) The competitor release effect applied to carnivore species: how red foxes can increase in numbers when persecuted. Anim Biodivers Conserv 36:37-46

Luengos-Vidal EM, Lucherini M, Casanave E (2003) An evaluation of three restraining devices for capturing pampas foxes. Canid News 6:1. http://www.canids.org/canidnews/6/Devices_for_capturing_pampas_foxes.pdf Accesed 30 October 2015

MAGRAMA (2011) Directrices técnicas para la captura de especies cinegéticas predadoras: 

homologación de métodos de captura y acreditación de usuarios. Ministerio de Agricultura, Alimentación y Medio Ambiente, Conferencia Sectorial de Medio Ambiente, Madrid

Manly BFJ, McDonald LL, Thomas DL, McDonald TL, Erickson WP (2002) Resource selection by animals. Kluwer Academic Publishers, Dordecht

Monterroso P, Brito JC, Ferreras P, Alves PC (2009) Spatial ecology of the European wildcat in a Mediterranean ecosystem: dealing with small radio-tracking datasets in species conservation. J Zool 279:27-35

Muñoz-Igualada J, Shivik JA, Domínguez FG, Lara J, González LM (2008) Evaluation of cage-traps and cable restraint devices to capture red foxes in Spain. J Wildlife Manage 72:830-836

Muñoz-Igualada J, Shivik JA, Domínguez FG, González LM, Aranda-Moreno A, Olalla MF, García CA (2010) Traditional and New Cable Restraint Systems to Capture Fox in Central Spain. J Wildlife Manage 74:181-187

O’Connell AF, Nichols JD, Karanth KU (2011) Camera Traps in Animal Ecology. Methods and Analyses. Springer, London

Powell RA, Proulx G (2003) Trapping and marking terrestrial mammals for research: integrating ethics, standards, techniques, and common sense. ILAR 44:259-276

Proulx G, Cattet MRL, Powell RA (2012) Humane and efficient capture and handling methods for carnivores. In: Boitani L, Powell RA (eds) Carnivore Ecology and Conservation: A Handbook of Techniques. Oxford University Press, London, pp 70129

Reynolds JC, Tapper SC (1996) Control of mammalian predators in game management and conservation. Mammal Rev 26:127-156

Ripple WJ, Estes JA, Beschta RL, Wilmers CC, Richie EG, Hebblewhite M, Berger J, 

(2014) Status and ecological effects of the world's largest carnivores. Science 343:1241484

Rodríguez A, Delibes M (2004) Patterns and causes of non-natural mortality in the Iberian lynx during a 40-year period of range contraction. Biol Conserv 118:151-161

Rosalino LM, Macdonald DW, Santos-Reis M (2004) Spatial structure and land cover use in a low density Mediterranean population of Eurasian badgers. Can J Zoolog 82:14931502

Shivik JA, Martin DJ, Pipas MJ, Turnan J, DeLiberto TJ (2005) Initial comparison: jaws, cables, and cage-traps to capture coyotes. Wildlife Soc Bull 33:1375-1383

459 Sutherland WJ (2006) Ecological Census Techniques. A Handbook. Second Edition. Cambrigde University Press, New York

461

Virgós E, Travaini A (2005) Relationship between Small-game Hunting and Carnivore 
Figure caption

466

467 Fig. 1. The true selectivity index, B (standardised W), changes according to the relative

468 abundance of two species in a community when the capture proportion for the two species

469 remains constant (species $1,0.7$ and species 2, 0.3). Where relative abundance for species 1 is

470 high (0.8, Figure 1 point $\left.A_{1}\right)$ and that for species 2 is low (0.2, Figure 1 point $\left.A_{2}\right)$, the

471 standardised index of selectivity, B, for species 1 is small (0.37) and that for species 2 is large

472 (0.63). Where species 1 is present at low relative abundance $\left(B_{1}\right)$ and species 2 at high relative

473 abundance (point $B_{2}$ on Fig. 1), the relative value for B is reversed: large for species 1 (0.90)

474 and small for species 2 (0.10).

475

476

477

478

479

480

481

482

483

484

485

486

487

488

489

490

491

492

493

494

495

496

497

498

499

500

501

502

503

504 
505

506

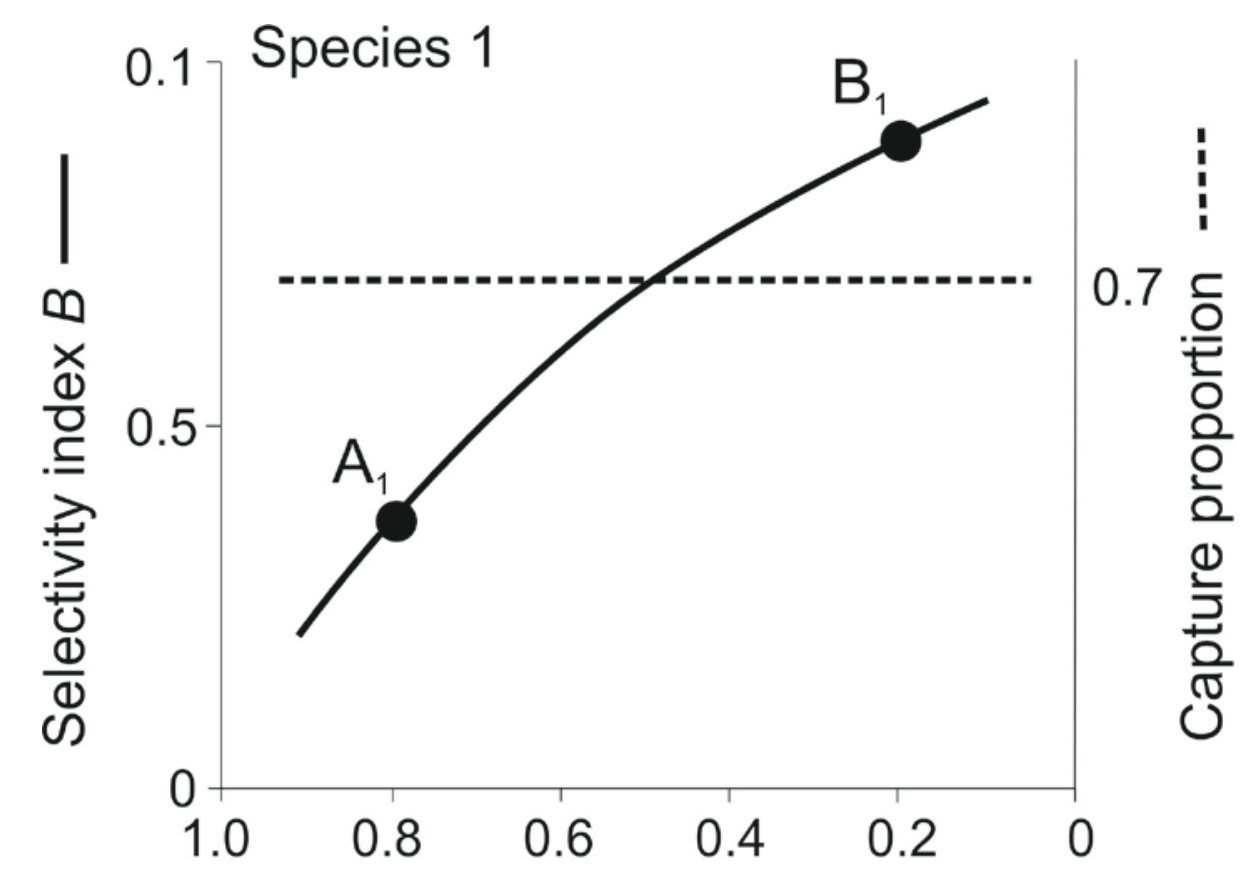

Figure 1

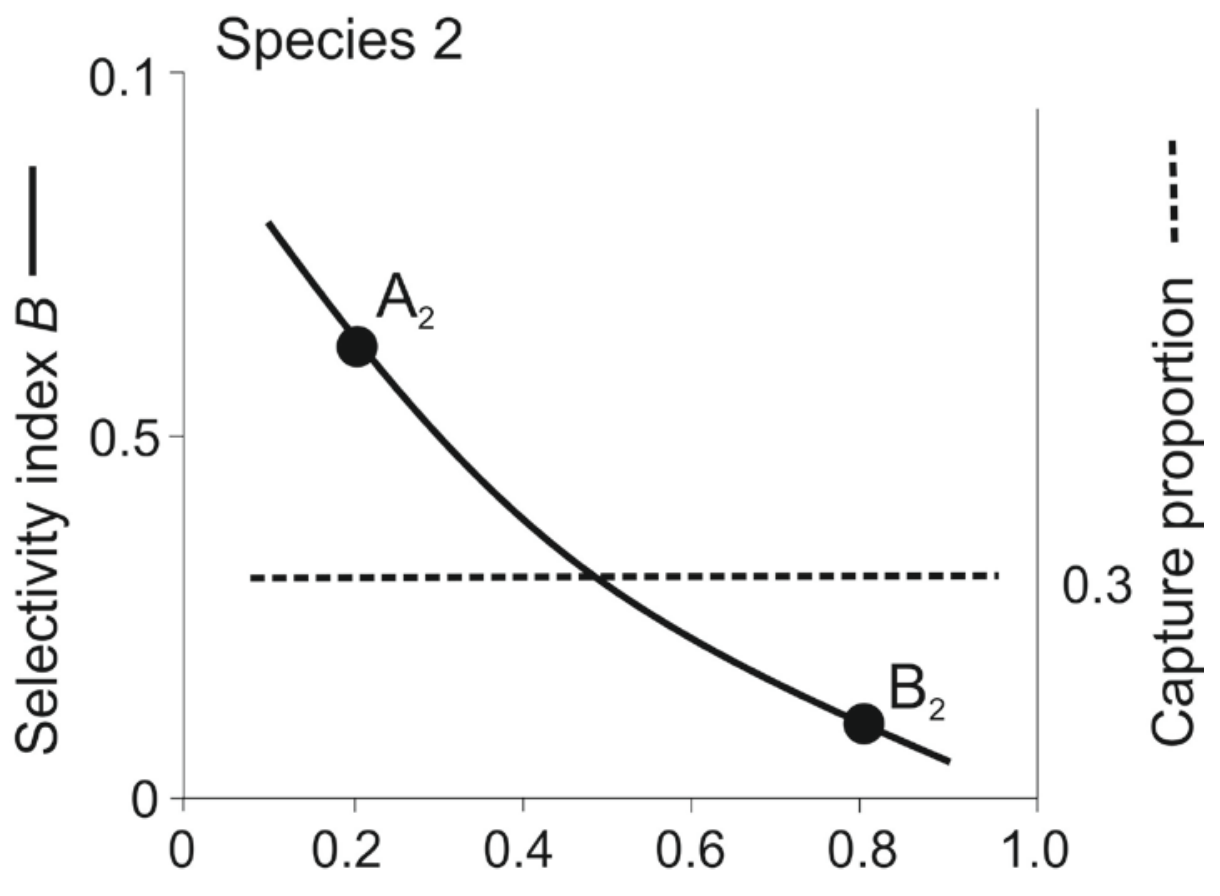

508

509

510

511

512

513

514

515 
516 Table 1. Illustration of the lack of selectivity represented by the ISO selectivity index, using

517 five hypothetical scenarios for trapping foxes and sympatric species in Mediterranean

518 environments. The table shows the Manly selectivity index (W=capture proportion/population

519 proportion), B (values of $\mathrm{W}$, standardised such that they sum to 1.0 , and can therefore be

520 compared across scenarios), relative species abundance, expected capture frequencies

521 according to relative species abundance (if species captured at random, i.e. no selectivity),

522 capture proportion under the $\mathrm{H}_{0}$ of no selectivity (number of captured target animals/total

523 number of captured animals, this equates to the ISO index), observed capture frequencies

524 under five scenarios (representing the proportion of species captured) and $\chi^{2}$ and P-values

525 associated with differences between expected and observed frequencies. Data for non-fox

526 captures were combined for statistical purposes (assumptions of the $\chi^{2}$ test depend on

527 expected values being sufficiently large; a convention that they are not $\leq 5$ is widely used).

528 Statistically significant selectivity in capture frequencies for fox and non-fox species

529 compared with that based on relative species abundance were demonstrated only where $\geq 90 \%$

530 of animals captured were foxes (scenarios 4 and 5, see P-values in bold). W for foxes

531 approximates to 1 where the proportion of foxes captured is close to the relative abundance of

532 foxes, this indicates random capture of (no selectivity for) this species; see scenarios 1, 2 and

533 3). Where $\mathrm{W}$ is significantly greater than 1 for foxes, trapping is selective for this species (see

534 scenarios 4 and 5). Selectivity (W) is greater for wildcats than foxes under scenarios 1 and 2. 


\begin{tabular}{|c|c|c|c|c|c|c|c|c|}
\hline Species & W & B & $\begin{array}{c}\text { Relative } \\
\text { species } \\
\text { abundance }\end{array}$ & $\begin{array}{c}\text { Expected } \\
\text { (based on } \\
\text { relative } \\
\text { species } \\
\text { abundance) }\end{array}$ & $\begin{array}{c}\text { Capture } \\
\text { proportion } \\
\text { (ISO } \\
\text { selectivity } \\
\text { index) }\end{array}$ & $\begin{array}{l}\text { Observed } \\
\text { (based on } \\
\text { ISO } \\
\text { selectivity } \\
\text { index) }\end{array}$ & $\chi^{2}$ & $\mathrm{P}$ \\
\hline Scenario 1 & & & & & & & & \\
\hline Red fox & 0.94 & 0.2 & 0.64 & 12.8 & 0.6 & 12 & & \\
\hline Wildcat & 1.25 & 0.27 & 0.12 & 2.4 & 0.15 & 3 & & \\
\hline Badger & 0.62 & 0.13 & 0.16 & 3.2 & 0.10 & 2 & & \\
\hline Stone marten & 1.87 & 0.4 & 0.08 & 1.6 & 0.15 & 3 & & \\
\hline Total & 4.69 & 1.00 & 1.00 & 20 & 1.00 & 20 & 0.139 & 0.71 \\
\hline
\end{tabular}

\begin{tabular}{|c|c|c|c|c|c|c|c|c|}
\hline Scenario 2 & & & & & & & & \\
\hline Red fox & 1.09 & 0.30 & 0.64 & 12.8 & 0.7 & 14 & & \\
\hline Wildcat & 1.25 & 0.35 & 0.12 & 2.4 & 0.15 & 3 & & \\
\hline Badger & 0.62 & 0.17 & 0.16 & 3.2 & 0.1 & 2 & & \\
\hline Stone marten & 0.62 & 0.17 & 0.08 & 1.6 & 0.05 & 1 & & \\
\hline Total & 3.59 & 1.00 & 1.00 & 20 & 1.00 & 20 & 0.313 & 0.58 \\
\hline
\end{tabular}

\section{Scenario 3}

\begin{tabular}{|c|c|c|c|c|c|c|c|}
\hline Red fox & 1.25 & 0.41 & 0.64 & 12.8 & 0.80 & 16 & \\
\hline Wildcat & 0.83 & 0.27 & 0.12 & 2.4 & 0.1 & 2 & \\
\hline Badger & 0.31 & 0.10 & 0.16 & 3.2 & 0.05 & 1 & \\
\hline Stone marten & 0.63 & 0.21 & 0.08 & 1.6 & 0.05 & 1 & \\
\hline Total & 3.02 & 1.00 & 1.00 & 20 & 1.00 & 20 & $2.222 \quad 0.14$ \\
\hline \multicolumn{8}{|l|}{ Scenario 4} \\
\hline Red fox & 1.41 & 0.66 & 0.64 & 12.8 & 0.9 & 18 & \\
\hline Wildcat & 0.42 & 0.19 & 0.12 & 2.4 & 0.05 & 1 & \\
\hline Badger & 0.31 & 0.15 & 0.16 & 3.2 & 0.05 & 1 & \\
\hline
\end{tabular}




\begin{tabular}{|c|c|c|c|c|c|c|c|c|}
\hline Stone marten & 0 & 0 & 0.08 & 1.6 & 0 & 0 & & \\
\hline Total & 2.13 & 1.00 & 1.00 & 20 & 1.00 & 20 & 5.87 & 0.02 \\
\hline \multicolumn{9}{|l|}{ Scenario 5} \\
\hline Red fox & 1.48 & 0.78 & 0.64 & 12.8 & 0.95 & 19 & & \\
\hline Wildcat & 0.42 & 0.22 & 0.12 & 2.4 & 0.05 & 1 & & \\
\hline Badger & 0 & 0 & 0.16 & 3.2 & 0 & 0 & & \\
\hline Stone marten & 0 & 0 & 0.08 & 1.6 & 0 & 0 & & \\
\hline Total & 1.90 & 1.00 & 1.00 & 20 & 1.00 & 20 & 8.34 & 0.004 \\
\hline
\end{tabular}

